\title{
A pedagogical design pattern framework \\ - for sharing experiences and enhancing communities of practice within online and blended learning
}

\section{Michael May}

PhD, Part time teacher

Department of Design and Communication, University of Southern Denmark

\section{Chresteria}

\section{Neutszky-Wulff}

MA, Assistant Lecturer

SAXO Institute, University of Copenhagen

\section{Susanne Rosthøj}

PhD, Associate Professor

Department of Public Health, University of Copenhagen
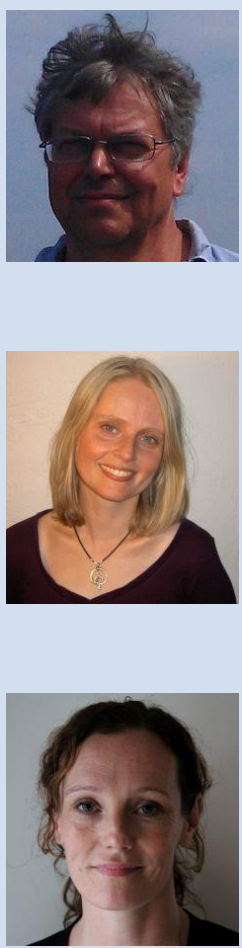


\section{Inez Harker-Schuch}

\section{MSc, Assistant Lecturer}

Department of Plant and Environmental Science, University of Copenhagen

\section{Victoria Chuang}

MSc, Research Assistant

Department of Plant and Environmental Science, University of Copenhagen

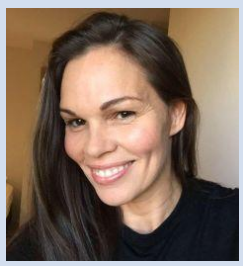

\section{Henrik Bregnhøj}

PhD, E-learning Consultant

Center for Online and Blended Learning, University of Copenhagen
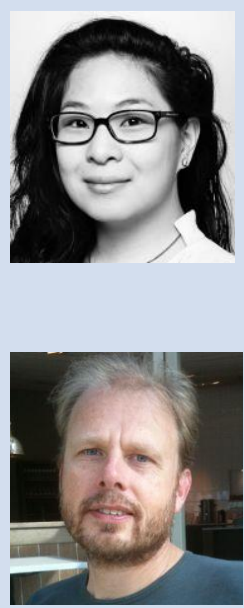

\section{Christian Bugge}

\section{Henriksen}

PhD, Associate Professor

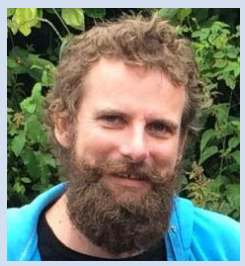

Department of Plant and Environmental Science,

University of Copenhagen 


\section{Abstract}

"Design patterns" were originally proposed in architecture and later in software engineering as a methodology to sketch and share solutions to recurring design problems. In recent years," pedagogical design patterns" have been introduced as a way to sketch and share good practices in teaching and learning; specifically, in the context of technology-enhanced learning (elearning). Several attempts have been made to establish a framework for describing and sharing such e-learning patterns, but so far they have had limited success. At a series of workshops in a competence-development project for teachers at the University of Copenhagen a new and simpler pedagogical design pattern framework was developed for interfaculty sharing of experiences and enhancing communities of practice in relation to online and blended learning across the university. The framework of pedagogical design patterns were applied to describe the learning design in four online and blended learning courses within different academic disciplines: Classical Greek, Biostatistics, Environmental Management in Europe, and Climate Change Impacts, Adaptation and Mitigation. Future perspectives for using the framework for developing new E-learning patterns for online and blended learning courses are discussed.

\section{Introduction and theoretical framework}

The idea of design patterns was originally proposed by Christopher Alexander (Alexander et al 1977; 1979) as a way to describe functional and beautiful buildings and places of the vernacular traditions in architecture and urban design. According to Alexander good architectural design on any scale from individual building elements to whole town areas constitute a kind of pattern language that has developed through experience with good solutions to recurrent problems of dwelling, playing, working, transportation and other activities.

In the 1990s design patterns were developed by analogy into a quasi-formal graphical language to describe alternative solutions to recurrent problems in software engineering within object-oriented programming languages (Gamma et al 1995). The focus was on established good practices of programming, as well as on the intelligibility and reusability of generic solutions that could then be adapted to specific circumstances and objectives. Design patterns were accordingly used to teach software engineering in order to help students structure and document their programming, but also to assist reasoning about alternative solutions.

This framework was later extended to include "anti-patterns" of bad practices to avoid (Brown et al 1998) as well as specialized design patterns for interaction design (Tidwell 2005). Inspired by the widespread use of design patterns in teaching software engineering and interaction design there is now a growing interest in extending the concept to university teaching, and 
specifically within technology enhanced learning (Goodyear \& Retalis 2010; Kohls \& Wedekind 2011; Mor et al 2014).

These "e-learning patterns" will, however, have to be seen as specific patterns for the pedagogically and didactically motivated use of digital media and information technologies as resources within a broader conception of teaching and learning. We need, in other words, a broader conception of pedagogical design patterns to articulate what works in teaching and learning, within which we can situate specific uses of media and technology. Such a conception has been worked out by Diana Laurillard in her reconceptualisation of teaching as a design science (Laurillard 2012).

In Laurillard's framework teachers are basically designers of didactic situations and learning environments. Knowledge and conceptual understanding cannot be "transmitted" directly, but has to be constructed by students through their collaborative work and active involvement with the resources made available within didactic situations and learning environments. Laurillard goes on to suggest that teachers could benefit from building on the designs of others, articulating their pedagogy, adopting, adapting, testing and improving learning designs and argues that a computational representation of pedagogic designs could facilitate the cocreation and sharing of learning designs (Laurillard 2013).

Several attempts have previously been made to create a platform or framework for sharing e-learning designs, but so far they have either been very basic like the pedagogical patterns toolbox in cloudworks (Conole and Culver 2010), heavily text-based like the exemplars on the Learning Designs repository (Agostinho 2011), highly structured and complex like COLLAGE (Hernandez-Leo et al 2006), or more like a "microworld" of concrete exercises on specific topics like the designs in Learning Designer (Laurillard 2013). In order for a pedagogical design pattern framework to be useful in a broader context it needs to balance simplicity with complexity and describe generalized pedagogical patterns which are not limited to specific topics and contexts of teaching, and not limited to either fully online or online and blended learning courses, but can be used across different academic disciplines and for both fully online and blended learning courses

Such a pedagogical pattern framework could benefit from being more closely linked to the original design pattern framework which features an introductory paragraph setting the context for the pattern (and how it helps to complete some larger patterns), a title and description of the problem, a description and a diagrammatic representation of the solution, and a link to smaller patterns which are needed to complete and embellish the pattern (McAndrew et al 2006). 


\section{Methodology for developing the pedagogical design pattern framework}

As a part of a competence development project at the University of Copenhagen from 2013 to 2016, a number of teachers involved with online and blended learning were invited to share their experiences with different "elearning models". The project was not designed as a research project with predefined methodologies or theoretical assumptions to be tested, but as a development project with a loosely defined objective of sharing experiences with the use of different "models" of "e-learning".

The idea of trying to specify these "models" through the framework of pedagogical design patterns arose gradually in discussions among the participants, and it was motivated by an initial uncertainty about how "elearning models" could be conceptualized - beyond the rough distinction between "online learning" and "blended learning" courses. The sketching of pedagogical design patterns in this way turned out to serve two different aims: one aim was to allow teachers, consultants and researchers within the project to conceptualize what we were already doing in terms of technology enhanced teaching, and another aim was to explore these patterns as a way to communicate experiences to other teachers.

The pedagogical design patterns were gradually introduced through examples and then outlined and reconstructed by the involved participants through a series of three workshops. At the first workshop the idea of pedagogical design patterns was introduced and a first set of examples presented. The main example used to illustrate the idea of a pedagogical design pattern was "flipped classroom" teaching, because this was known to all teachers in the project.

Flipped classroom teaching is a good case to discuss, because it is often misunderstood. Flipped classroom teaching is sometimes confused with the use of video lectures as a resource to realize the pedagogical objective of "the flipping". The use of video is, however, optional for the flipping. The main pedagogical idea of "flipped classroom" is not to use video lectures, but to move lecturing and other forms of introductions and overviews into student's homework in order to focus the time spend with students on interactive tasks like collaborative problem solving and discussion. Video-recorded lectures can be used as a tool, but so can books, journal papers and audio podcast to mention a few other media. Flipped classroom teaching as a pedagogical design pattern is accordingly not defined by the use of video lectures. 
During the first workshop teachers worked on sketching parts of their own teaching as a design pattern or as a series of linked design patterns, and these sketches were then presented on flip charts.

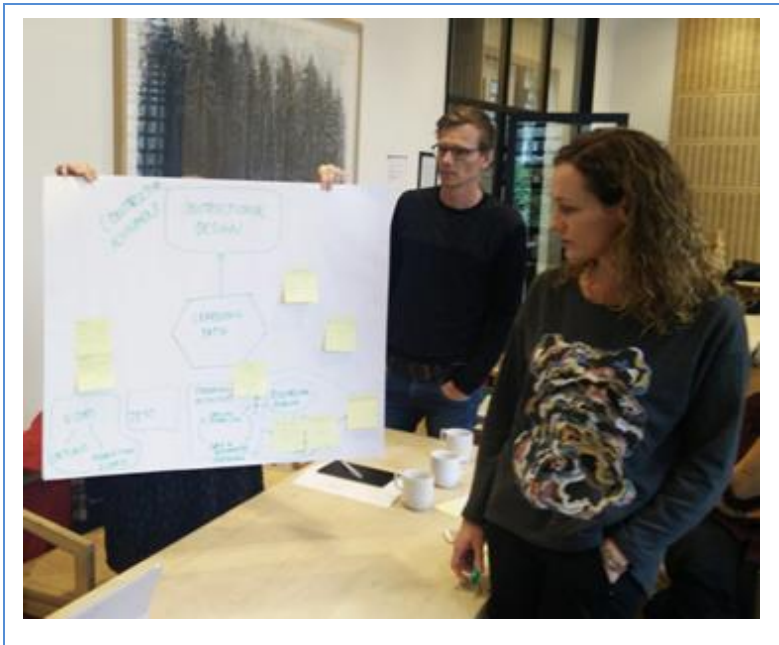

Figure 1. Susanne Rosthøj presenting the first sketch of the Learning Path pattern for her blended biostatistics course at the first workshop.

Prior to the second workshop these sketches were reviewed and redrawn by one of the researchers in an attempt to harmonize the sketches and propose a common graphical and logical layout for the patterns without requiring a full pattern language. In this process some of the original ideas behind the first sketches were inadvertently distorted or omitted, and therefore a third workshop was needed to restate the proposed models of e-learning in a coherent and mutually agreed form.

At the third workshop teachers shared the full pedagogical design patterns for their courses - taking the harmonized proposals into account - and the final version of the pedagogical design pattern framework was formulated.

\section{Description of the developed design pattern framework}

There is no consensus on how to represent design patterns, although there is agreement about what a pattern should minimally include. The key elements are a recurrent problem of teaching and learning (or alternatively, an intention to design a new course or optimize an old one), a suggested pedagogical solution, and the context of this in the form of use cases, i.e. courses using the proposed pattern presently or in the future. Furthermore, problems and solutions should be described in a generalized form in order for patterns to be applicable across disciplinary domains. Design patterns have to be adapted and elaborated to specific contexts (Goodyear \& Retalis 2010) and can be considered as abstractions over good practices. It is important to stress 
that teaching can never have a singular "best practice"; design patterns can only be abstractions over "good practices".

In addition to this, however, design patterns should abstract from specific technologies. As mentioned above, "flipped classroom" teaching is sometimes described as the video-recording of lectures, but patterns should not be linked tightly to specific technologies, but defined through their pedagogical rationale.

The pedagogical design pattern framework developed in the project features the following elements:

- Motivation(s) for applying a given pattern

- Meta-pattern(s) (including learning principles)

- Pedagogical design pattern(s)

- Description

- Activities (performed by teachers, tutors and students)

- Resources (including media and tools)

- Use cases

- Macro-pattern(s)

\section{Motivation(s) for applying a given pattern}

Each pedagogical design pattern, and more specifically each "e-learning pattern", will be motivated as a possible solution to a set of recurrent problems in teaching and learning, or alternatively as a possible (experimental) improvement to teaching and learning or as a possible organization of a new course. This rationale for the pattern is important to include, because this is where pedagogical design patterns are identified as abstractions over good practices rather than just descriptions of practices and the use of technologies. Notice that the rationale for a pattern will sometimes be based in experience (when trying to solve a problem in teaching), and sometimes in the expected effects of a design or redesign.

\section{Meta-pattern(s)}

As abstractions over good practices in teaching, many pedagogical design patterns will be able to refer to general principles of teaching and learning. Example of such general principles could be "active learning", "problem-based learning" and "inquiry-based learning". These principles will often refer to theories and models such as different constructivist learning theories, but the pedagogical design patterns should not include theories in their description, although we might want to refer briefly to a principle on a meta-level above the specific pattern. Similarly it might be relevant to reflect on the organization of patterns and include references to more general patterns, to alternative patterns, and even advice on what not to do (this is called "antipatterns" in the software design pattern literature).

If we, for instance, posit Gilly Salmon's Five Stage Model (Salmon 2002) as a pedagogical design pattern, it will be useful to indicate that this is a specific 
pattern for the temporal and social organization of online activities, and that we might have other good practices for organizing online activities. Another example could be a design pattern for organizing online journal club discussions. Here it would be relevant to indicate that online journal clubs are an online version of a more general pattern for journal club discussions, i.e. sharing features with journal club meetings that are not implemented through online discussions. The more general patterns are here called meta-patterns.

\section{Pedagocial design patterns}

Description: Formally a pedagogical design pattern is identified through a short descriptive name and a short explanatory description of the idea of the pattern - independent of the specific course example. The specific example is a use case, and this is where details of the implementation and the potential experiences of its use can be described.

Activities: A pedagogical design pattern will always specify a set of activities performed by teachers, and possibly also tutors and students. This can be difficult to detach from the specific use cases, but usually there will be a "core" set of activities and situations that are independent of specific courses and disciplines. A pattern for flipped classroom, for example, will - according to the motivation for this pattern - include a set of activities distributed between student's homework and students in-class activities. The generic aspects of these in-class activities will be the focus on student-centered work with difficulties encountered during their individual homework (or group work), as well as teacher or tutor moderated discussions and problem solving activities in class. The actual content of this activity will of course depend on the disciplines (and belong to the individual use cases).

Resources: When talking about "e-learning patterns" or pedagogical patterns for technology-enhanced learning it is important to detach these patterns from specific technologies. "Using clickers" or "Using video-lectures on YouTube" are not by themselves pedagogical patterns. We need to specify why we introduce in-class voting systems such as clickers, and we need to detach the pattern from a particular technology ("clickers"), because voting on conceptual questions in class can be realized in different ways using different technologies. The resources used in any given pattern could include many different media and tools, but they are not in themselves constituting the pattern. As stated above we might use video-recorded lectures as a resource for flipped-classroom teaching, but we might alternatively use audio podcasts or written lecture notes.

Use cases: The use cases are references to the cases where the patterns have been applied (or are going to be applied).

Macro-patterns:

A macro-pattern in the pedagogical design pattern framework, is a combination of patterns that constitute a part of or an entire online and blended learning course. It is different from the meta-patterns in the sense that meta-patterns are involved in an abstraction hierarchy (online journal 
clubs are an instantiation and a further specification of the more abstract pattern of journal clubs in general), whereas macro-patterns have parts that are patterns. A course will usually build on a large aggregation of different pedagogical design patterns rather than just a single one.

\section{Examples of pedagogical design patterns}

The developed pedagogical design pattern framework was subsequently applied for describing the learning design in four online and blended learning courses within different academic disciplines at the University of Copenhagen: Classical Greek, Biostatistics, Environmental Management and Climate Change. The online course Classical Greek and the blended learning course Regression Analysis for Medical Research Year Students share a common macro-pattern that we have called "Learning path" (see Figure 2 and 3), and the two online courses Environmental Management in Europe and Climate Change Impacts, Adaptation and Mitigation share the common macro-pattern that we have called "Asynchronous interactive online inquiry" (see Figure 4). The macropatterns and a few examples of the individual patterns for the courses are presented and described below.

The online course Classical Greek and the blended learning course Regression analysis for medical research year students are very similar, even though the courses are run by two different faculties. During the common work with mapping the learning patterns of the courses the similarities became obvious and, as a result, the two course teachers have been able to work closely together exchanging experiences and developing their courses.

This common work would have been more difficult without the design patterns to guide and visualize the dialogue, providing the teachers with a common pedagogical framework. Specific common challenges were:

1. Both courses have a very steep learning curve. If the students don't keep up, they will quickly fall behind, and as a result, students often drop out.

2. The students have an urgent need for scaffolding and high guidance learning consisting of rote learning and training. They often have difficulties explaining their needs. 
3. They have a strong need for an oral dialogue as well as ongoing immediate feedback on their activities from the teacher and/or fellow students.

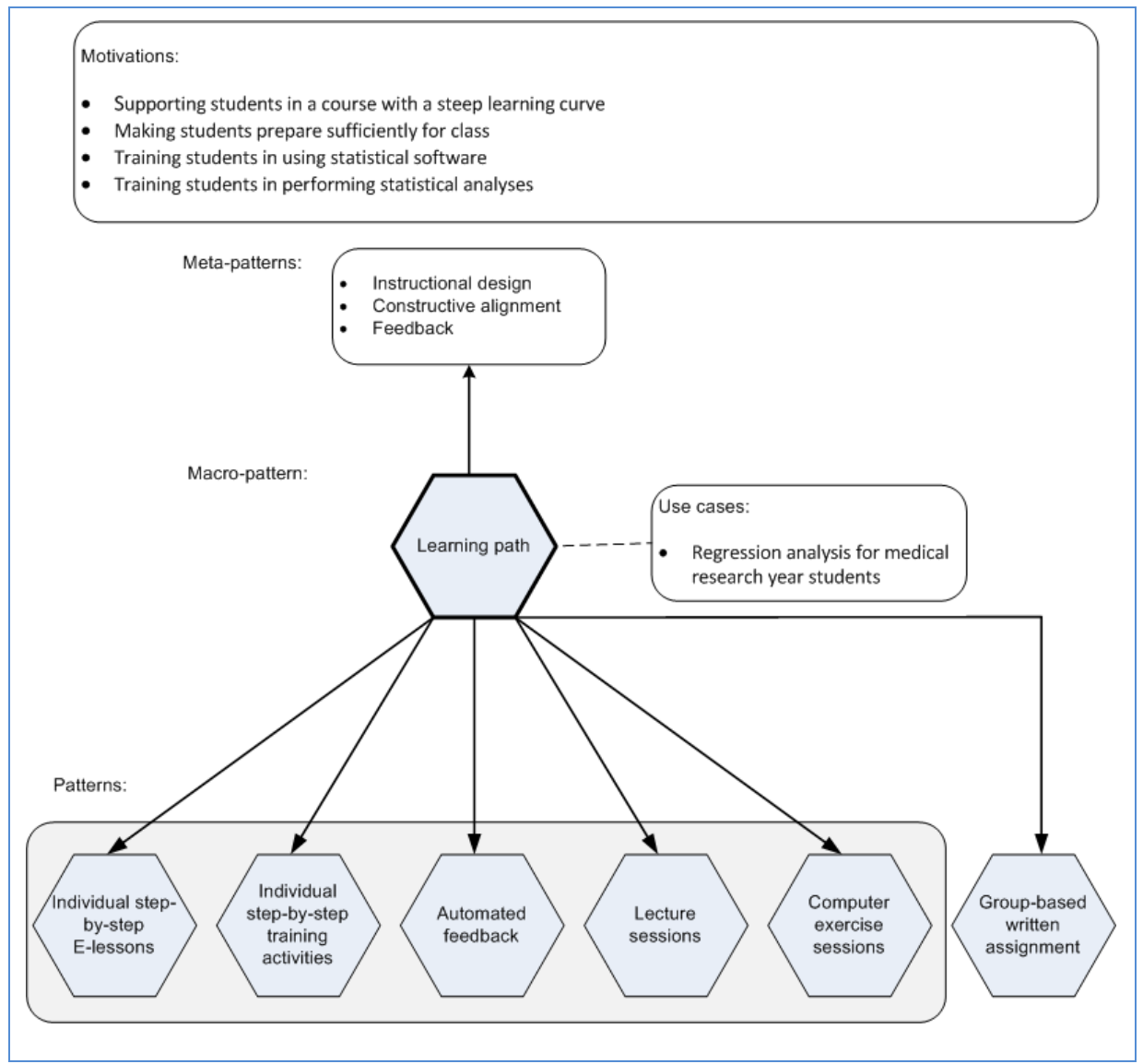

Figure 2. Learning path macro-pattern in the Regression Analysis course. The box around some of the patterns indicate recurrent patterns used every week.

Regression Analysis for Research Year Students (cf. Figure 2) is an intensive course for medical research year students. Besides being taught biostatistical methods, the students are introduced to a command-based statistical software program. The course consists of six weekly traditional classroom sessions, each session containing three lectures followed by three hours of computer labs. Becoming familiar with the statistical methods and the statistical software program requires training, and in particular rote learning is needed to learn the technical programming details of using the statistical software. Specific challenges teaching this course, besides 1.-3. mentioned above, are that students often do not prepare sufficiently for the lectures. As part of this project we have tried to use a wide range of online tools to aid the students with their work:

- Facilitating the students' preparation for the classroom sessions by being specific on and preparing their preparation (elements from flipped classroom). 
- Supporting the training of the use of statistical methods and programming between teaching sessions. The students are carefully guided through the activities as these are broken into small steps with a high level of guidance. Frequent and immediate feedback are given using online quizzes supplemented by online chat fora.

To pass the course the students have to complete at least $80 \%$ of the weekly training activities as well as a group based written report with a low level of guidance. The teaching structure is described in more detail in (Rosthøj, 2014). The learning path macro-pattern in the Regression Analysis for Research Year students is composed of the following patterns:

1. Individual step-by-step E-lessons (cf. Figure 5).

2. Step-by-step training activities

3. Immediate online feedback

4. Lecture sessions

5. Computer labs

6. Group based written assignment

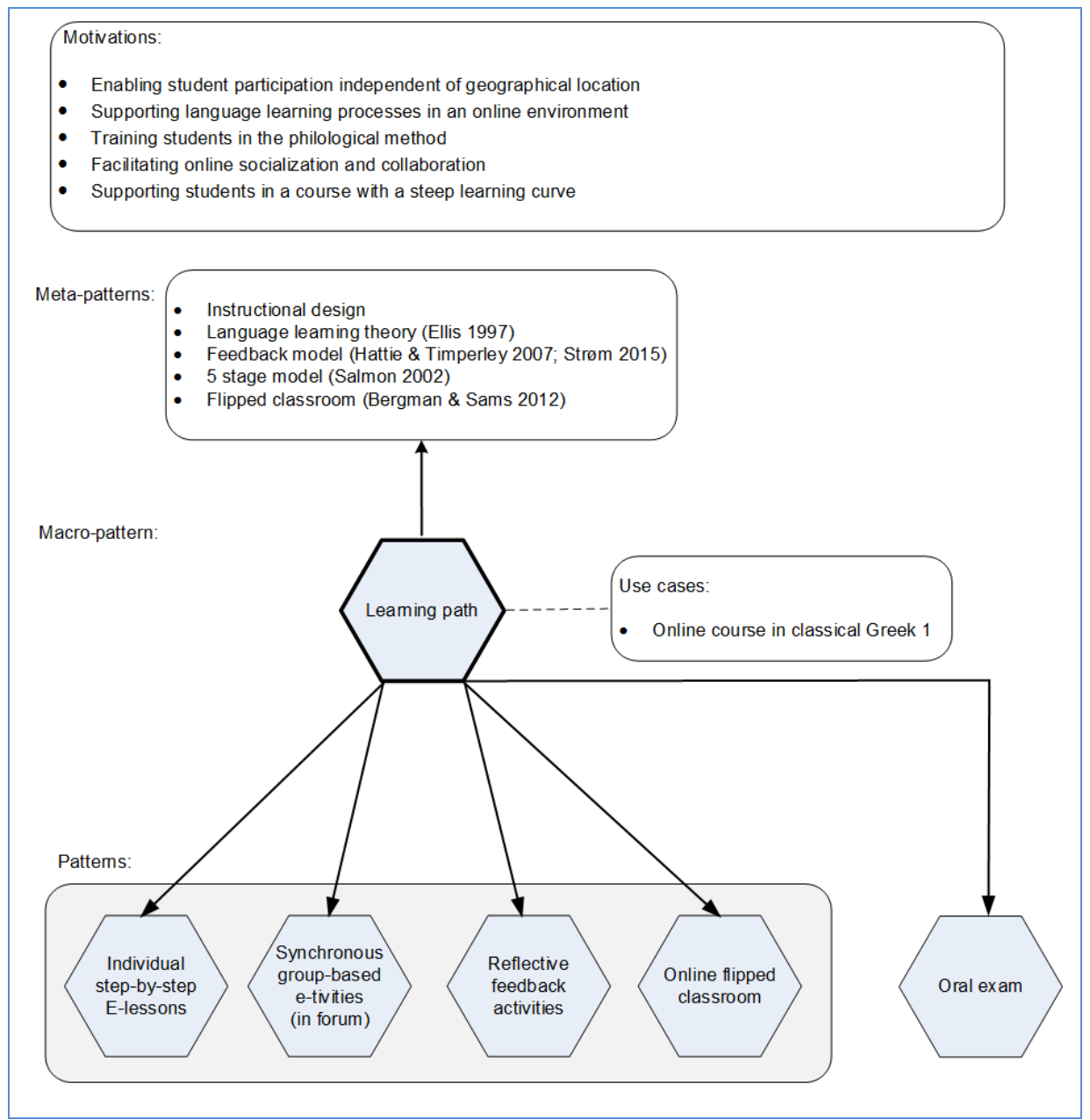

Figure 3. Learning path macro-pattern in the Classical Greek course

The course in Classical Greek (cf. Figure 3) is an online course using feedbackbased learning paths and weekly assignments. It is primarily a language 
course for beginners with elements of culture, the learning outcome being reading skills and grammatical analysis. It is a $30(3 \times 10)$ ECTS course over three terms (level 1-3) offered by the SAXO Institute at the Faculty of Humanities, UCPH. During the course, the students advance from learning the Greek alphabet to reading original texts such as Plato and Homer.

There is a lot of rote learning and training involved in the course. Learning a set of basic forms and a basic vocabulary by heart make the students able to navigate through the text in an easier way. The philological method is learned by extensive training of the basic principles. The students are often high school teachers who are studying Classical Civilization at UCPH via Open University. Some are historians or study science of religions. They all have other study or work obligations, and therefore need a flexibly planned course. No need to say, that this is a very specialized subject with only few students (less than 10 per level) and very few resources.

Each level consists of 14 lessons over a period of 14 weeks combined with 2 half day seminars at UCPH. The students hand in one written and/or oral assignment per week followed by feedback (in different forms) from the teacher. The written communication between teacher and students is supplemented by one online meeting every three weeks (Neutzsky-Wulff, 2009; Neutzsky-Wulff, 2010).

An additional key challenge of teaching this course other than 1.-3. mentioned above is that the students have very different backgrounds and qualifications for language learning. Therefore, in the online and blended learning (OBL) project, we have tried to:

- Support method training at level 1 by breaking the weekly lessons into small training steps with a high level of guidance, showing the students how to analyze a text step by step. This includes quizzes and other forms of exercises with automated feedback.

- Strengthen the online socialization process by using the discussion forum for weekly synchronous chats (Monday chats) focusing on getting the students started with the weekly assignments (levels 1, 2 and 3).

- Grade the written assignments in different ways in order to make the students reflect more on their learning process and generally to provide better and more differentiated feedback (levels 1, 2 and 3).

- Flip the classroom in the online meeting sessions to activate the students more during the synchronous oral dialogue (levels 1, 2 and $3)$.

This effort has resulted in the following design patterns for the course. The patterns are related, more than one pattern being part of the same activity. For example, step-by-step lessons may lead up to a flipped online session, while the E-tivities in the discussion forum are part of these lessons as well as an ingredient in the feedback on written assignments. 
1. Individual step-by-step E-lessons

2. Synchronous group-based E-tivities in the discussion forum

3. Reflective feedback activities

4. Online flipped classroom

5. Oral exam

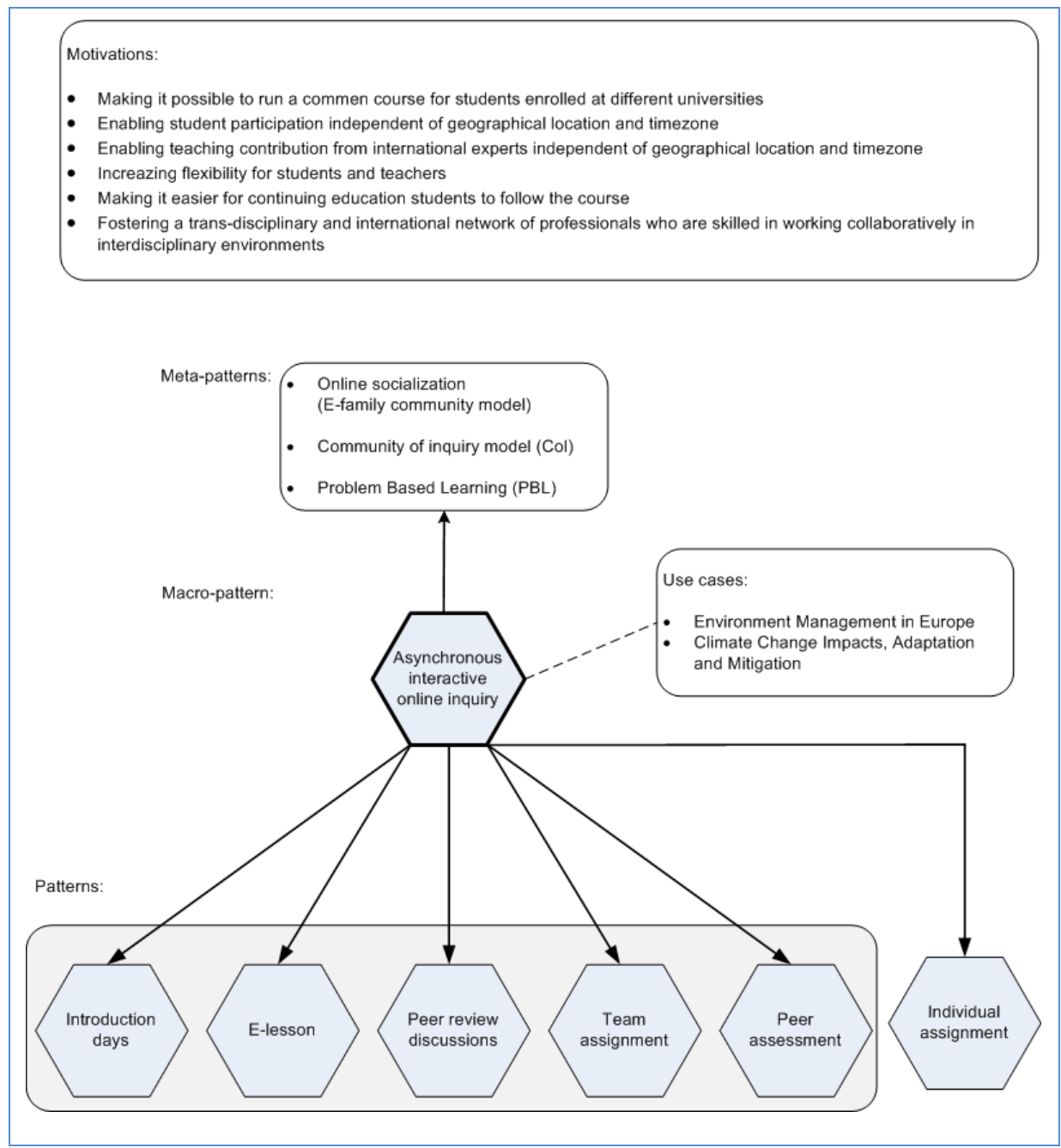

Figure 4. Asynchronous interactive online inquiry macro-pattern

We will now describe two online courses on environmental management and climate change (Henriksen et al 2010). These courses are very similar in structure and they are run by the Faculty of Science. They can be described through an asynchronous interactive online inquiry macropattern (cf. Figure 4). The courses Environmental Management in Europe and Climate Change Impacts, Adaptation and Mitigation share the following characteristics:

1. mandatory 15 ECTS courses in a MSc programme at the University of Copenhagen (MSc in Environmental Science/EnvEuro and MSc in Climate Change, respectively) 
2. two introduction days in the beginning of the course before going $100 \%$ online for the rest of the course

3. learning activities which are based on pedagogical design patterns for asynchronous online discussions (E-tivity based E-lessons), team assignments and individual assignments

4. assessment based on submission of a portfolio of deliverables from E-lessons, team assignments and individual assignments

5. both courses feature peer assessment and peer review patterns

The asynchronous interactive online inquiry macro-pattern combine metapatterns of Online Socialization, Community of Inquiry and Problem Based Learning (PBL). The essence of the macro-pattern is the creation of an online learning community in the form of an E-family Community model further developed from Gilly Salmon's Five Stage Model (Salmon 2002) with E-kids (students), E-siblings (tutors), E-professors (teachers) an E-dad/E-mom (course administrator) and an E-godfather/E-godmother (course leader). Teachers and tutors provide guidance to assist students in constructing knowledge together and moving through the phases of practical inquiry (Garrison et al 2000), by completing a number of e-learning modules (Emodules) featuring discussion based e-lessons as well as problem based team assignments and individual assignments. The motivations for running the courses with the asynchronous interactive online inquiry macro-pattern are to:

1. Make it possible to run a common course for students enrolled at different universities (four partner universities are involved in the MSc in Environmental Science - Soil, Water and Biodiversity (EnvEuro)

2. Enable student participation independent of geographical location and timezone (which will potentially increase the number of students on the course)

3. Enable teacher contribution from international experts (teachers from Oxford University, University of Essex, UC Berkeley and Australian National University have contributed)

4. Increase flexibility for students and teachers (both students and teachers can log on and contribute to the online discussions any time during the day/night)

5. Make it easier for continuing education students to follow the course (several continuing education students have followed the courses due to the flexibility)

6. Fostering a transdisciplinary and international network

The asynchronous interactive online inquiry macro-pattern in the online courses Environmental Management in Europe and Climate Change Impacts, Adaptation and Mitigation is composed of the following patterns: 
1. Introduction days

2. E-tivity based E-lessons

3. Peer-review discussion

4. Team assignment

5. Peer assessment

6. Individual assignment

The patterns for all three courses can be found in the online supplement, which is available at:

https://docs.google.com/document/d/1B1FxieyT8ghLF0daXxIaBj9ajLPL WhHoVKlC4lPybRw

Below we present different versions of the E-lesson pattern that we discovered were used across our different example courses. Reflecting on her course Regression Analysis for Medical Research Year Students Susanne Rosthøj defined an "Individual step-by-step E-lessons pattern" as describing her (blended learning) course design (cf. Figure 5). This pattern turned out to be very closely related to the pattern for e-lessons employed by Chresteria Neutzsky-Wulff in her (online) course in Classical Greek (Figure 6). 


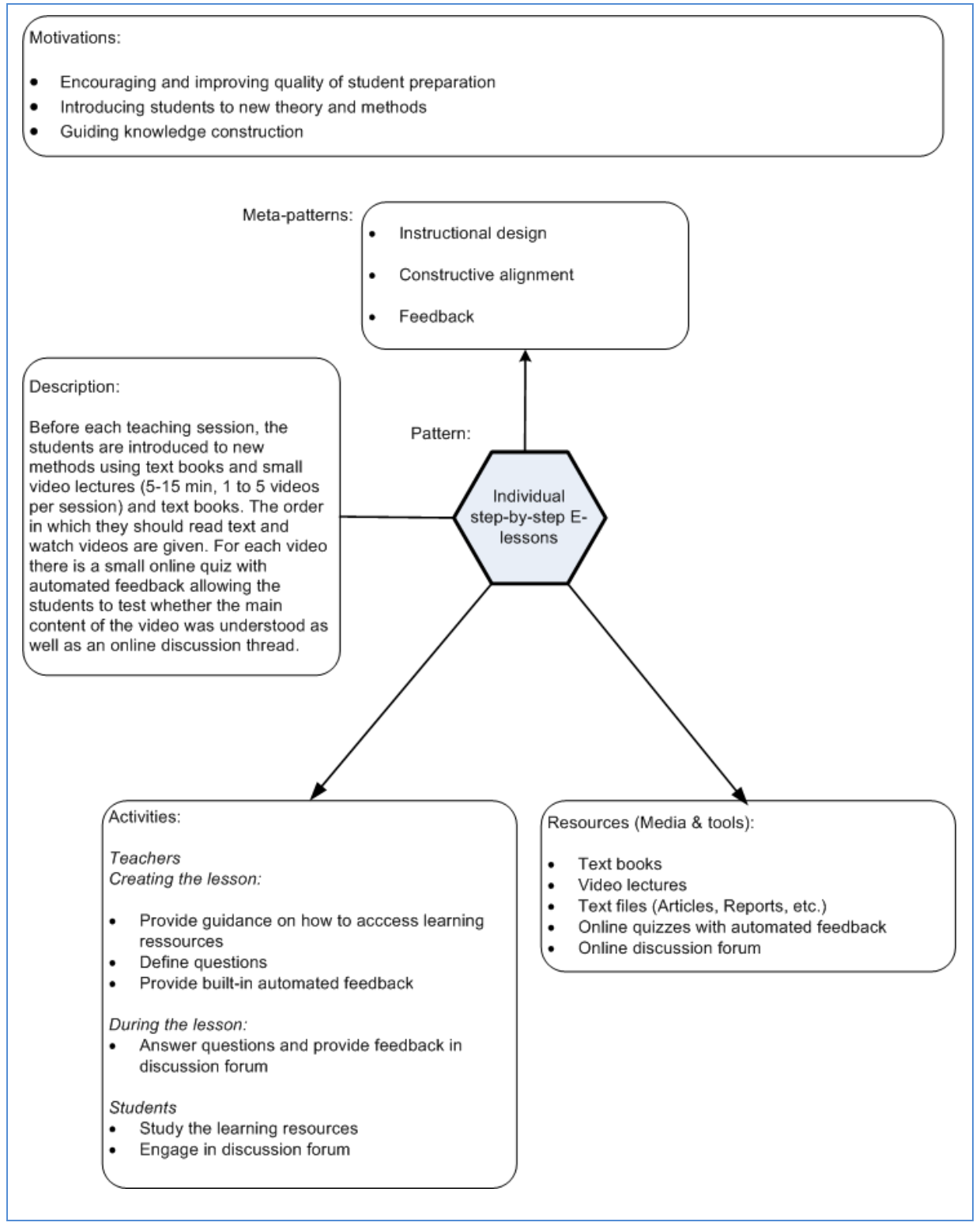

Figure 5. The "Individual step-by-step e-lessons pattern" as sketched for the course in Regression Analysis for Medical Research Year Students.

This similarity was debated and although we here present two individual design patterns to capture the differences between the courses, we also considered the alternative of suppressing these differences in the pattern and express the course-specific details in the use case information. In the end we thought it was necessary to maintain two versions of the pattern, among other things to show that the specific setup of the Classical Greek course results from the application of "flipped classroom" ideas in a fully online course (Neutzsky-Wulff, 2009; Neutzsky-Wulff, 2010). 


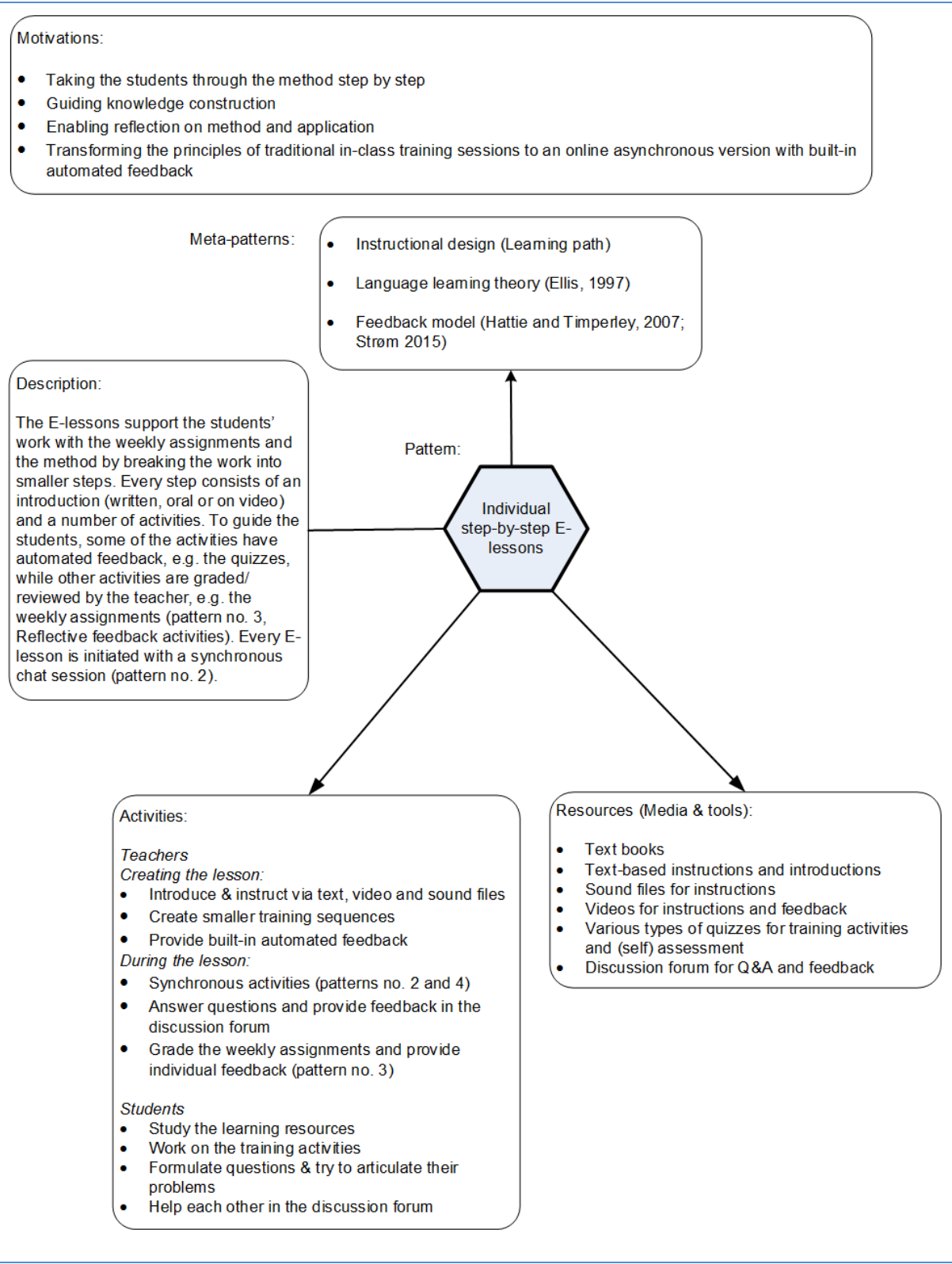

Figure 6 The "Individual step-by-step e-lessons pattern" as sketched in the online course in Classical Greek. Notice similarities with the similar pattern in Figure 5.

A similar argument can be given about the e-lesson pattern used in the environmental management and climate change courses (cf. Figure 7). Here the "E-tivity based E-lesson pattern" shared by the two courses also implements a form of E-lesson pattern, but since it has been modified to fit into the overall conception of the courses according to the E-family Community model described above (and expressed in the macro-pattern for the course), it makes sense to specify E-tivity based E-lessons as a specific version of E-lessons.

As a consequence we could argue that E-lessons in general should be schematized as a meta-pattern although we have not detailed it here. 
Motivations:

- Enabling asynchronous online interaction

- Guiding knowledge construction in online learning communities

- Providing relevant feedback to students

- Facilitating student reflectioin on ouwn learning outcome

- Accomodating different work/life schedules

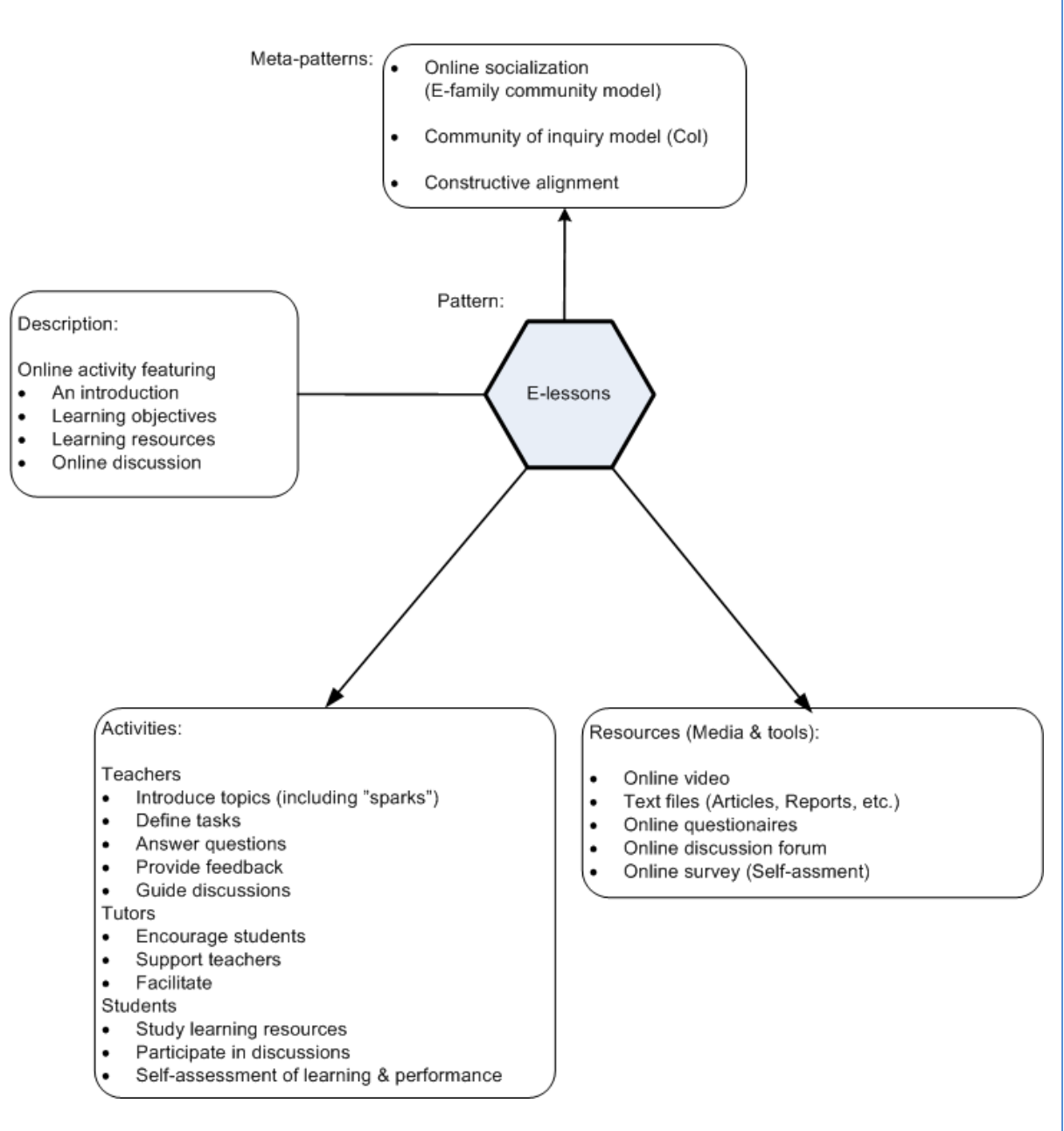

Figure 7 The "E-tivity based E-lesson pattern" as sketched for the two courses on environmental management and climate change.

\section{Discussion and future perspectives}

The idea of using pedagogical design patterns in the competence development project on Online and Blended Learning (OBL) at the University of Copenhagen was developed and discussed gradually in the project group. Learning theories as taught in pedagogical teacher training courses will often be seen as difficult to implement in concrete teaching activities. Although abstract principles like "active learning" and "inductive teaching" might seem appealing to teachers, the burden of applying such principles to actual 
teaching is often left to course responsible teachers without the support of a "community of practice" for sharing experiences in teaching and learning. Although the original concept of a "community of practice" (Lave \& Wenger 1991 and Wenger 1998) was formulated in contrast to formal learning by "transmission" of knowledge, it makes sense to reconsider its usefulness within higher learning communities (Lea, 2005; Jakovljevic et.al. 2013). The project created an opportunity for teachers to spend time with colleagues on figuring out what they were already doing in their experimentation with different forms of "e-learning". Since the involved teachers came from different faculties and the involved course topics ranged from "Classical Greek" to "neutron scattering", it was necessary to abstract from the actual content of courses and find a way to analyze and redesign different "models of e-learning". All the teachers in the project, despite their different backgrounds, participated because of their interest in the use of digital media for teaching, and a lot of the discussions evolved around specific digital media, eg. video or quizzes. Often, digital tools tend to attract a lot of the attention while designing teaching and learning activities, but as we were working with the design pattern model, we were reminded to view digital media as tools (resources among other types of resources) to achieve our pedagogical goals.

Models in science are generally a way to specify theories into more practical entities that explain, predict or design particular situations in order for them to be examined through empirical work. Models are closer to practical reality than theories, and in natural science models are needed for the design of experiments. The pedagogical design patterns are a way to address this level of modeling in teaching, or - in other words - a way to build a bridge between the abstract level of pedagogical theories and the principles of learning theories, on one hand, and the practical reality of teaching specific courses under specific circumstances, on the other hand.

It is imperative, however, that the patterns we formulated were developed by teachers themselves, although the process was also guided by pedagogical consultants and researchers. The patterns will only work if they are recognized as core patterns actually deployed by the involved teachers. Another imperative for their usefulness was that they were discussed over a longer period of time among colleagues, or - in other words - that they were developed to communicate good practices of teaching within a "community of practice". This also points to a limitation of the approach: we believe that it will only work effectively within a community or network of teachers actually working together within a project or with the planning of shared teaching responsibilities. Sharing patterns across the internet could work within a virtual community sharing a project, but not for teachers trying to impose a pattern - created by someone else in a different context and for different purposes - on a course without actively engaging in its rationale and reorganizing it to adapt it to the new context. 
It is thus foreseeable that the benefits of formulating and analyzing design patterns under these circumstances will also indicate the limitations of the method. We find that the process has been relevant and useful within the project, and it might also be beneficial for the university on a larger scale in so far as it can be associated with a community of practice sharing experiences in teaching and learning. Scaling up the experience for sharing pedagogical design patterns on the internet - within a global community that do not actually share cultural practices of teaching - will, in our view, not be rational. The exchange of patterns will always have to rely on a local "community of practice" or at least a virtual community actually working together within a project, where graphical sketches and pattern descriptions will be understood in the same way or negotiated within a shared setting.

We will propose two dilemmas that restrict the rationality of the use of pedagogical design patterns:

- The dilemma of formalization: Some amount of formalization is helpful for schematization of the patterns such as the different types of relations involved (is_a, has_a, and link relations). We found it necessary, as we have seen, to distinguish meta-patterns from macro-pattern, but a rigorous pattern language as it is known in software engineering would pose a pragmatic problem for the formulation of patterns by teachers. To exemplify we can mention the highly complex Educational Modelling Language (EML) and the attempts to formalize pedagogical design patterns within a full diagrammatic language such as coUML.

- The dilemma of scalability: Locally and on a limited scale a collection of patterns can be formulated and maintained by a group of teachers and researchers within the same "community of practice" (or virtual community) for sharing of good practices in teaching. Scaling up this activity for sharing between communities on a larger scale, as we have seen with regard to the global internet-based sharing of "learning objects" (May et.al 2010) and whole courses, would pose a pragmatic problem, however, because large collections of patterns would require extensive work of identifying similar patterns and maintaining the coherency of pattern formulations. This is often overlooked in "visionary" proclamations about the future of "e-learning" as the global sharing of learning content and forms of teaching. Besides the problem of maintaining large pattern collections, there is also the pragmatic problem of negotiation of meaning: on a small scale a local community of practice or a virtual community can negotiate how to interpret diagram sketches and pattern descriptions, but on a larger scale this is not feasible.

Despite these dilemmas we find the developed design pattern framework highly useful. One of the most surprising and useful discoveries working with the pedagogical design pattern framework was the ability for teachers to work together across faculties and course topics. During the discussions a need arose for discussion at different levels, describing the actual problems and 
challenges of the specific courses and at the same time exchanging ideas at a more general pedagogical level.

By describing pedagogical design patterns on a higher level than the actual course topics, we discovered striking similarities between two at first glance very different courses. In fact the courses were so similar at their pedagogical core that a close exchange of experiences and ideas took place. This is where the community of practice on pedagogical design patterns has shown its full potential, and we encourage other communities and networks of teachers to engage in a similar process to facilitate the cross-pollination of ideas and the creation of new learning designs. 


\section{References}

Agostinho, S. (2011): The use of a visual learning design representation to support the design process of teaching in higher education. Australasian Journal of Educational Technology 27, pp 961-978

Alexander, C., Ishikawa, S., Silverstein, M., Jacobson, M., Fiksdahl-King, I. \& Angel, S. (1977): A Pattern Language: Towns, Buildings, Construction. Oxford University Press.

Alexander, C. (1979): The Timeless Way of Building. Oxford University Press.

Brown, W.J., Malveau, R.C., McCormick, H.W., Mowbray, T.J. (1998): AntiPatterns: Refactoring Software, Architectures, and Projects in Crisis. John Wiley \& Sons.

Bergman, J. \& Sams, A. (2012): Flip Your Classroom: Reach Every Student in Every Class Every Day. International Society for Technology in Education.

Conole, G., Culver, J. (2010): The design of Cloudworks: Applying social networking practice to foster the exchange of learning and teaching ideas and designs. Computers \& Education 54, pp 679-692

Ellis, R. (1997): Second Language Acquisition. Oxford Introductions to Language Study. Oxford: Oxford University Press.

Garrison, D. R., T. Anderson and W. Archer (2000): Critical inquiry in a textbased environment: Computer conferencing in higher education. The Internet and Higher Education 2: 87-105.

Gamma, E., Helm, R., Johnson, R., \& Vlissides, J. (1995). Design Patterns: Elements of Reusable Object-Oriented Software. Addison-Wesley.

Goodyear, P. \& Retalis, S. (Eds)(2010): Technology-Enhanced Learning: Design Patterns and Pattern Languages. Sense Publishers.

Hattie, J. \& Timperley, H. (2007): The Power of Feedback. Review of Educational Research, March 2007, Vol. 77, No. 1, 81-112.

Henriksen, C.B., Monty, A., Porter, J.R. (2010): Globalt læringsmiljø om et globalt problem - en beskrivelse af et tværvidenskabeligt online kursus om klimaforandringer. Læring og medier, 3 (6), http://ojs.statsbiblioteket.dk/index.php/lom/article/view/3906/3414

Hernandez-Leo, D., Villasclaras-Fernandez, E.D., Asensio-Perez, J.I., Dimitriadis, Y., Jorrin-Abellan, I.M., Ruiz-Requies, I., Rubia-Avi, B. (2006): COLLAGE: A collaborative learning design editor based on patterns. Educational Technology \& Society 9, pp 58-71

Jakovljevic M, Buckley S, Bushney M. (2013): Forming communities of practice in higher education: a theoretical perspective. Proceedings of the Management, Knowledge and Learning International Conference; Zadar, Croatia. June 19-21, 2013. 
Kohls, C. \& Wedekind, J. (Eds) (2011): Investigations of E-Learning Patterns: Context Factors, Problems and Solutions. IGI Global/Information Science Reference.

Koper, R. and Manderveld, Jocelyn (2004). Educational modelling language: modelling reusable, interoperable, rich and personalised units of learnings, British Journal of Educational Technology, Vol 35(5), 537-551.

Laurillard, D. (2012). Teaching as a Design Science: Building Pedagogical Patterns for Learning and Technology. Taylor \& Francis.

Laurillard, D., Charlton, P., Craft, B., Dimakopoulos, D., Ljubojevic, D., Magoulas, G., Masterman, E., Pujadas, R., Whitley, E. A., Whittlestone, K. (2013): A constructionist learning environment for teachers to model learning designs. Journal of Computer Assisted Learning 29, pp 15-30

Lave, J. \& Wenger, E. (1991). Situated learning: Legitimate peripheral participation. Cambridge University Press.

Lea M. (2005): Communities of practice in higher education. Useful heuristic or educational model? . In: Barton D, Tusting K, editors. Beyond communities of practice: language, power and social context. Cambridge University Press.

McAndrew, P., Goodyear, P. \& Dalziel, J. (2006). Patterns, designs and activities: unifying descriptions of learning structures. International Journal of Learning Technology, 2(2-3), 216-242.

May, M. et.al. (2010): Constraints on reusability of learning objects: Didactic aspects of modular e-Learning in engineering education. Proceedings of the 2nd International Conference on Computer Supported Education (CSEDU 2010), 325- 332.

Mor, Y., Mellar, H., Warburton, S. \& Winters, N. (Eds) (2014): Practical Design Patterns for Teaching and Learning with Technology. Sense Publishers.

Neutzsky-Wulff, C. (2009): Nærhed i fjernundervisning - om brugen af audio og video i sprogundervisning. Læring og medier, 2 (2), http://ojs.statsbiblioteket.dk/index.php/lom/article/view/3915

Neutzsky-Wulff, C. (2010): Nærværende fjernundervisning - et projekt om ikt-støttet feedback. Læring og medier, 3 (6),

\section{http://ojs.statsbiblioteket.dk/index.php/lom/article/view/3938/3445}

Rosthøj, S. (2014): Undervisning baseret på færdighedstræning - via online aktiviteter med løbende feedback. Læring og Medier, 7 (12), http://ojs.statsbiblioteket.dk/index.php/lom/article/view/17280/159 $\underline{47}$

Salmon, G. (2002): E-tivities: The Key to Active Online Learning. Routledge. 
Strøm, Sophie Holm (2015): Synlig læring i gymnasiet og på HF. - Baglæns design af undervisningen med synlige læringsmål, succeskriterier og løbende feedback. Dafolo.

Tidwell, J. (2005): Designing Interfaces: Patterns for Effective Interaction Design. (2nd edition, 2010). O'Reilly Media.

Wenger, E. (1998): Communities of Practice. Learning, Meaning and Identity. Cambridge University Press. 